\title{
Different reactivity to glutathione but similar tumor cell toxicity of chalcones and their quinolinone analogues
}

\author{
Giulio D. C. d'Oliveira ${ }^{1,2}$ - Jean M. F. Custodio ${ }^{1} \cdot$ Andrea F. Moura $^{3} \cdot$ Hamilton B. Napolitano $^{4} \cdot$ Caridad N. Pérez $^{1}$. \\ Manoel O. Moraes ${ }^{3} \cdot$ László Prókai $^{5} \cdot$ Pál Perjési $\mathbb{B}^{2}$
}

Received: 17 March 2019 / Accepted: 13 June 2019 / Published online: 1 July 2019

(C) The Author(s) 2019

\begin{abstract}
Non-enzyme catalyzed nucleophilic addition of reduced glutathione (GSH) onto two open-chain sulfonamide chalcones and two quinolinone-chalcone hybrids were studied to investigate the relationship between tumor cell cytotoxic activities and GSH-reactivities of the compounds. The consumption of the chalcones or the quinolinone-chalcone hybrids due to conjugation with GSH was evaluated by analytical high-performance liquid chromatography, and the formed diastereomeric adducts were identified by liquid chromatography-mass spectrometry. When the reaction was conducted with the open-chain chalcones, the equilibria were shifted towards formation of the respective GSH-conjugates. On the other hand, the cyclic chalcone derivatives with the quinolinone moiety were found to equilibrate to mixtures containing predominantly the reactants despite the strong electron withdrawing group present in the B-ring of the compounds. The observed opposite behavior can be rationalized by reduced thiol-reactivity of the quinolinone-chalcone hybrids and fast decomposition of their GSH-conjugates. A combined X-ray diffraction and theoretical approach were used to explain the observed difference in the reactivities towards GSH. However, structural differences did not influence tumor cell (SF-295, PC-3 and HCT-116) cytotoxicity of the evaluated compounds. Accordingly, the altered GSH-reactivity seems to be not a determining factor in the tested tumor cell cytotoxic activity of the investigated compounds.
\end{abstract}

Keywords Chalcones $\cdot$ Quinolinone $\cdot$ Glutathione $\cdot$ Michael reaction $\cdot$ Tumor cell cytotoxicity.

Pál Perjési

pal.perjesi@gytk.pte.hu

pal.perjesi@gmail.com

1 Instituto de Química, Universidade Federal de Goiás, Goiânia, Goiás 74690-900, Brazil

2 Institute of Pharmaceutical Chemistry, University of Pécs, Pécs H-7624, Hungary

3 Núcleo de Pesquisas e Desenvolvimento de Medicamentos, Universidade Federal do Ceará, 60430-270 Fortaleza, Ceará, Brazil

4 Ciências Exatas e Tecnológicas, Universidade Estadual de Goiás, Anápolis, Goiás 75132-903, Brazil

5 Department of Pharmacology and Neuroscience, Institute of Healthy Aging, Graduate School of Biomedical Sciences, University of North Texas Health Science Center, Fort Worth, Texas 76107, USA

\section{Introduction}

Chalcones are intermediary compounds of biosynthetic pathways of a very large and diverse group of plant constituents known collectively as flavonoids (Harborne and Williams 2000). Among the naturally occurring chalcones and their synthetic analogs, several compounds displayed cytotoxic (cell-growth inhibiting) activity towards cultured tumor cells. Chalcones also are effective in vivo as cellproliferation inhibitors, anti-tumor promoting, antiinflammatory and chemopreventive agents (Go et al. 2005; Nowakowska 2007; Amslinger 2010; Rahman 2011; Sahu et al. 2012; Maydt et al. 2013; Sing et al. 2014; Rozmer and Perjési 2016; Gomes et al. 2017; Zhuang et al. 2017).

Nucleophilic addition of cellular thiols onto the polarized carbon-carbon double bond (Michael-reaction) is frequently associated with the biologic effects of chalcones and other $\alpha, \beta$-unsaturated carbonyl compounds (Go et al. 2005; Nowakowska 2007; Amslinger 2010; Maydt et al. 2013; Gomes et al. 2017; Perjési et al. 2019). Such a reaction 
involving reduced glutathione (GSH) can alter intracellular redox status (redox signaling), which can modulate events such as DNA synthesis, enzyme activation, selective gene expression, and regulation of the cell cycle Modification of cellular redox status through GSH-conjugation could result in both desired and undesired (e.g., cancer resistance) effects of the compounds (Powis et al. 1997; Estrela et al. 2006; Ortega et al. 2011; Traverso et al. 2013; Harris et al 2015; Bansal and Simon 2018; Vasková 2019).

Several biological effects (e.g., NQO1-inducer (Dinkova-Kostova et al. 2001), anti-inflammatory (Jin et al. 2008; Amslinger 2010; Maydt et al. 2013;), GST P1-1 inhibitory (Wang et al. 2009) of chalcones have been associated with their Michael-type reactivity towards GSH. It was suggested that the lower anti-inflammatory potential of chalcones with strong electron donor substituents (e.g., dimethylamino) on the B-ring could be the consequence of the lower Michael-type reactivity of the derivatives towards GSH (Jin et al. 2008). On the other hand, higher reactivity towards GSH and other thiols were found to parallel with higher NQO1-inducing potential of the investigated chalcones (Dinkova-Kostova et al. 2001). The results highlighted importance of the GSH-conjugation of chalcones, which can be an important molecular event in the mechanism of their biological actions.

Structural modification of chalcones could result in different GSH-reactivity (Amslinger 2010; Maydt et al. 2013; Gomes et al. 2017). Earlier, we have investigated GSHreactivity of analogous 4'-hydroxychalcones and their bisMannich derivatives (Bernardes et al. 2017; Bernardes et al. 2018). It was found that the Mannich derivatives showed a significantly different reactivity (Bernardes et al. 2017) and stereoselectivity (Bernardes et al. 2018) from those of the respective non-Mannich derivatives when the reactions were conducted under acid conditions. Furthermore; we have synthesized several 2'-benzensulfonamido-chalcones and their cyclic quinolone derivatives (de Castro et al. 2016; de Castro et al. 2017; d'Oliveira et al. 2018). Some of the chalcones showed excellent inhibition of cell growth of HCT-116 (colon) tumor cells. On the contrary, only a small fraction of the cyclic analogues displayed comparable inhibitory activity (d'Oliveira et al. 2018).

In order to investigate how the conversion of the openchain $2^{\prime}$-sulfonamide chalcones to the respective quinolone derivatives affect the cytotoxicity and the GSH-reactivity, here we report on the GSH addition and tumor cytotoxic determination of two sulfonamide chalcones ( 2 and $\mathbf{3}$ ) and their cyclic quinolinone analogs (5 and 6) (Fig. 1). Compounds 5 and $\mathbf{6}$ have the same chalcone moieties as compounds $\mathbf{2}$ and $\mathbf{3}$, which allow comparison of GSH-reactivity towards the enone derivatives regarding this particular change in structure (i.e., open-chain versus cyclic quinolinone). For a better understanding of the observed

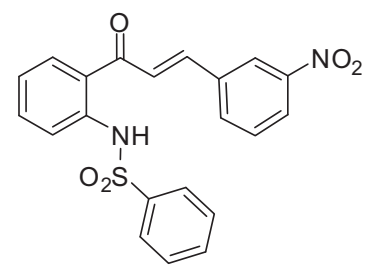

2

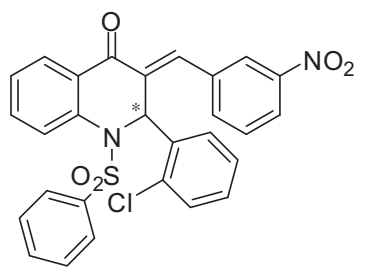

5

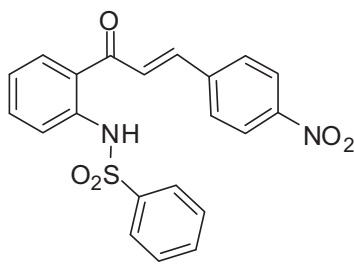

3

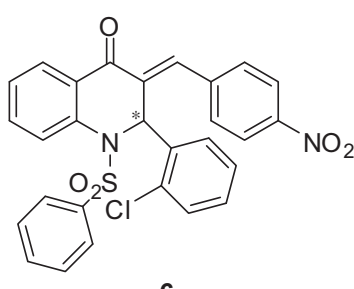

6
Fig. 1 Structural formula of chalcones $\mathbf{2}$ and $\mathbf{3}$ and quinolinones 5 and 6

differences in reactivity, the crystal structure of chalcones 2 and $\mathbf{5}$ was determined by X-ray diffraction, and theoretical calculations were performed. Cytotoxicity of the compounds was evaluated against the SF-295 (glioblastoma), PC-3 (prostate cancer) and the HCT-116 (colon cancer) tumor cell lines and the results were compared with the observed GSH-reactivities.

\section{Materials and methods}

\section{Synthesis}

\section{General Information}

Compounds 1, 2, 4, 5 and $\mathbf{6}$ were synthesized as published before (d'Oliveira et al. 2018). Characterization of the synthesized samples were accomplished by their melting points, and their ${ }^{1} \mathrm{H}{ }^{13} \mathrm{C} \mathrm{NMR}$, and HRMS spectra. The respective ${ }^{1} \mathrm{H}{ }^{13} \mathrm{C}$ NMR spectra (Figures $\mathrm{S} 1-\mathrm{S} 6$ ), ${ }^{13} \mathrm{C}$ NMR spectra (Figures S7-S12), and HRMS spectra (Figures S13S18) of the compounds can be found in the Supplementary Data.

Melting points were determined with the solid supported on glass coverslips using a Karl Kolb (Frankfurt, Germany) apparatus. NMR spectra were acquired on a Bruker (Bremen, Germany) Avance III 500 spectrometer operating at $11.75 \mathrm{~T}$, observing ${ }^{1} \mathrm{H}$ at $500.13 \mathrm{MHz}$ for the hydrogen nucleus or $125.76 \mathrm{MHz}$ for the carbon nucleus. The complete signal assignment was also obtained by heteronuclear multiple bond correlation (HMBC) and heteronuclear single quantum correlation (HSQC) experiments. Mass spectrometric analysis was performed using a Micro-TOF-Q III spectrometer (Bruker Daltonics, Bremen, Germany) 
equipped with a commercial ESI (electrospray ionization) ion source.

\section{Synthesis of $(E)$-3-(4-nitrophenyl)-1-(2- (phenylsulfonylamine)phenyl)prop-2-en-1-one (3)}

Compound 1 (275.1 mg, $1.0 \mathrm{mmol}$ ) and 4-nitrobenzaldeyde (151.1 mg, $1.0 \mathrm{mmol}$ ) were dissolved in $5 \mathrm{~mL}$ of dichloromethane, $5 \mathrm{~mL}$ of basic 2-propanol $(62.5 \mathrm{mg}$ of metallic sodium dissolved in $5 \mathrm{~mL}$ of 2-propanol) was added and the mixture was allowed at ambient temperature $\left(25^{\circ} \mathrm{C}\right)$ for $50 \mathrm{~min}$. Then $30 \mathrm{~mL}$ of dichloromethane was added, and the solution was extracted with water until the water phase became neutral. The dichloromethane phase was dried, and the crude product was purified via flash columns chromatography (normal phase; 7:3 hexane/acetate and pure dichloromethane) to afford a yellow crystalline powder (125 mg, 30.6\%). Mp 229-231 ${ }^{\circ} \mathrm{C} .{ }^{1} \mathrm{H}$ NMR $\left(\mathrm{CDCl}_{3}\right) \delta 7.16$ $(d d d, J$ 7.94, 7.34, $1.06 \mathrm{~Hz}, 1 \mathrm{H}), \delta 7.42(m, 2 \mathrm{H}), \delta 7.48$ $(m, 1 \mathrm{H}), \delta 7.51(d, J 15.60 \mathrm{~Hz}, 1 \mathrm{H}), \delta 7.53$ (ddd, $J 8.41$, $7.29,1.51 \mathrm{~Hz}, 1 \mathrm{H}), \delta 7.73(d, J 15.65 \mathrm{~Hz}, 1 \mathrm{H}), \delta 7.76$ $(m, 3 \mathrm{H}), \delta 7.87(m, 3 \mathrm{H}), \delta 8.30(m, 2 \mathrm{H}), \delta 11.22(s, 1 \mathrm{H}) ;{ }^{13} \mathrm{C}$ $\mathrm{NMR}\left(\mathrm{CDCl}_{3}\right) \delta 120.32,123.11,123.79,124.32,125.72$, $127.28,129.09,130.79,133.02,135.08,139.39,140.29$, 140.48, 142.56, 148.77, 191.97. HRMS calculated for $\mathrm{C}_{21} \mathrm{H}_{15} \mathrm{~N}_{2} \mathrm{O}_{5} \mathrm{~S}$ 407.0707, found 407.0713.

\section{Reactivity toward GSH}

\section{Michael reaction of compounds 2, 3, 5 and 6 with GSH}

To evaluate in vitro reactivity of the compounds towards GSH, $100 \mu \mathrm{L}$ of a freshly prepared $\mathrm{pH} 3.2$ aqueous solution of GSH (containing $1.875 \times 10^{-3}$ and $7.5 \times 10^{-3} \mathrm{mmol}$ for study at lower and higher concentration of GSH, respectively,) were mixed with $900 \mu \mathrm{L}$ of a freshly prepared DMSO solution containing $6.25 \times 10^{-4} \mathrm{mmol}$ of the chalcones $2, \mathbf{3}, \mathbf{5}$ and 6. The mixtures were incubated in a water bath at $37^{\circ} \mathrm{C}$, and the progress of the reactions was followed by HPLC with ultraviolet (UV) spectrophotometric detection. For HPLC analysis, $10 \mu \mathrm{L}$ of the incubate diluted with $990 \mu \mathrm{L}$ of mobile phase and immediately analyzed as described below (2.2.3.). Two parallel experiments were performed.

\section{Retro-Michael reaction of the conjugates}

In order to study the reverse (retro-Michael) reaction of the GSH conjugates to the respective chalcones, incubations were performed as described above using GSH solution of the higher $\left(7.5 \times 10^{-3} \mathrm{mmol}\right)$ concentration. After the equilibrium was reached (100 $\mathrm{min}$ for compounds $\mathbf{2}$ and $\mathbf{3}$, and $60 \mathrm{~min}$ for compounds 5 and $\mathbf{6}$ ), $10 \mu \mathrm{L}$ of the incubate was diluted with $990 \mu \mathrm{L}$ of a mixture of methanol/water
$(75: 25 \mathrm{v} / \mathrm{v})$. The obtained dilution was immediately analyzed by HPLC as described below. Analysis of the samples was repeated after 10, 20, 30, 40, 50 and 120 min standing at room temperature in the dark.

\section{HPLC-UV/Vis measurements}

HPLC analyses were performed with an Agilent 1100 (Agilent Technologies, Waldbronn, Germany) integrated system equipped with a quaternary pump, a degasser, an autosampler, and a variable wavelength UV-Vis detector. Data were recorded and evaluated by use of Agilent Chem Station (Rev. B.03.01) software.

The components were separated on a Zorbax Eclipse XDB-C8 column $(150 \times 4.6 \mathrm{~mm}, 5-\mu \mathrm{m}$ particle size; Agilent Technologies, Waldbronn, Germany) at room temperature. The flow rate was $1.0 \mathrm{~mL} \mathrm{~min}^{-1}$, and isocratic elution with a mobile phase of $25: 75 \mathrm{v} / \mathrm{v}$ mixture of water and methanol containing $0.1 \%(\mathrm{v} / \mathrm{v})$ trifluoroacetic acid was used. The injection volume was $20 \mu \mathrm{L}$. Detection was performed at $\lambda=302,321,302$ and $316 \mathrm{~nm}$ wavelength for the analysis of $\mathbf{2}, \mathbf{3}, \mathbf{5}$ and $\mathbf{6}$, respectively.

\section{HPLC-UV-ESI/MS investigations}

HPLC-UV-ESI/MS analyses were performed with an Ultimate 3000 UHPLC Focused Probe (Thermo Scientific, Germering, Germany) integrated system equipped with a quaternary pump, a degasser, an autosampler and a column compartment. The components were separated on the same Zorbax Eclipse XDB-C8 column $(150 \times 4.6 \mathrm{~mm}$, particle size $5 \mu \mathrm{m}$ ) used for the HPLC-UV/Vis assays. Chromatography was performed at $25^{\circ} \mathrm{C}$, with a flow rate of $1.0 \mathrm{~mL}$ $\min ^{-1}$ and the injection volume of $50 \mu \mathrm{L}$. For the elution of the compounds, a binary gradient was mixed from mobile phases A and B (A: water $0.1 \%$ formic acid; B: methanol $0.1 \%$ formic acid) by the following profile: $50 \%$ A: $50 \%$ B for $10 \mathrm{~min}$ followed by a linear program to $25 \% \mathrm{~A}: 75 \% \mathrm{~B}$ in $10 \mathrm{~min}$ to keep in this last solvent composition for $5 \mathrm{~min}$ before returning to the initial conditions in $1 \mathrm{~min}$ for an additional $4 \mathrm{~min}$ to equilibrate the column for the next injection. UV detection was performed at $302 \mathrm{~nm}$. The mass spectrometer was a Q Exactive ${ }^{\mathrm{TM}}$ Focus hybrid quadrupoleOrbitrap ${ }^{\mathrm{TM}}$ instrument (Thermo Scientific, Bremen, Germany) operated with electrospray ionization (ESI) in alternating positive and negative ion modes, as well as subsequent all-ion fragmentation to obtain tandem mass spectra (MS/MS) through collision-induced dissociation (CID) of both positive and negative ions within one cycle of acquisitions. Spray voltage and the capillary temperature of the Ion-MAX interface were held at $\pm 4.5 \mathrm{kV}$ at $300{ }^{\circ} \mathrm{C}$, respectively. The following ESI parameters were kept constant during the analysis: sheet gas and auxiliary gas 
(both $\mathrm{N}_{2}$ ) flow rates of 65 and 20 units (arbitrary), respectively; desolvation temperature of $500{ }^{\circ} \mathrm{C}$. All scans were recorded in the $\mathrm{m} / z, 100$ to $1000(\mathrm{Th})$ range with the mass resolution set to 35,000 at $\mathrm{m} / \mathrm{z} 400$. Data were recorded and evaluated using Thermo Scientific's Xcalibur ${ }^{\mathrm{TM}}$ software (version 4.1).

Identifications were supported by accurate mass measurements performed at high mass resolution. Mass accuracies (expressed as the difference between measured and expected $\mathrm{m} / \mathrm{z}$ ) were $<5 \mathrm{ppm}$. The chalcones gave predominantly negative ions, while the quinolonechalcone hybrids yielded mostly positive ions. The conjugates displayed in-source fragmentation to the ionized precursor compounds and ionized GSH. The assignment of these fragment ions was confirmed by their accurate masses both from the full-scan MS and the CID-MS/MS spectra.

\section{Crystallography}

Suitable single crystals of compounds $\mathbf{2}$ and $\mathbf{5}$ were collected at room temperature using the Bruker APEX II CCD diffractometer with graphite-monochromated $\mathrm{MoK} \alpha$ radiation $(\lambda=0.71073 \AA)$. The structures were solved by direct methods and refined by full-matrix least squares on $F^{2}$ using SHELXL2014 software (Sheldrick 2008), available on WingX suit programs (Farrugia 2012). Compound 2 $\left(\mathrm{C}_{22} \mathrm{H}_{16} \mathrm{~N}_{2} \mathrm{O}_{4} \mathrm{~S}\right)$, had its structure determined from 30977 reflections collected and 3950 unique reflections, while compound $\mathbf{5}\left(\mathrm{C}_{28} \mathrm{H}_{19} \mathrm{~N}_{2} \mathrm{O}_{5} \mathrm{ClS}\right)$, had its structure determined from 64756 reflections collected and 6703 unique reflections. All the hydrogen atoms were placed in calculated positions and refined with fixed individual displacement parameters $\left[\mathrm{U}_{\text {iso }}(\mathrm{H})=1.2 U_{\text {eq }}\right.$ or $\left.1.5 U_{\text {eq }}\right]$ according to the riding model (C-H bond lengths of 0.97 and $0.96 \AA$, for aromatic and methyl groups, respectively). The unit cells found measure: $a=14.0149(16) \AA \hat{,}, b=7.6562(9) \AA \hat{A}, c=$ $18.380(2) \AA$ and beta $=101.242(4) \AA$ for 2 and $\mathrm{a}=10.2889$

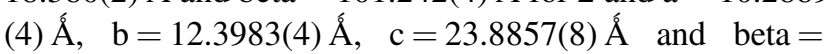
55.021(3) $\AA$ for 5. Molecular representations and pictures were generated by Mercury (Macrae et al. 2006) and Ortep (Farrugia 2012) programs.

\section{Theoretical calculations}

The starting geometries used in the calculations were taken directly from the X-ray data and their energies (single point) were calculated by using the Density Functional Theory (DFT) as implemented in the Gaussian 09 package of programs (Frisch et al. 2009). The extended Gaussian basis set 6-311 + $+\mathrm{G}(\mathrm{d}, \mathrm{p})$ of Pople and co-workers (Krishnan et al. 1980; Schlegel et al. 1984) with B3LYP functional (Yanai et al. 2004) were employed throughout the calculations.

\section{Antitumor tests}

Cytotoxicity of the compounds has been tested by means of the universally used MTT method (Skehan et al. 1980). The method was first described by Mosmann (Mosmann 1983), having the ability to analyze the viability and the metabolic state of the cells. This cytotoxicity study allows one to define cytotoxicity, but not the mechanisms of anticancer action (Berridge et al. 1996). Human tumor cell lines SF-295 (glioblastoma), PC-3 (prostate) and HCT-116 (colon) were used. The cells were given by the National Cancer Institute (USA) and cultured in Roswell Park Memorial Institute (RPMI) 1640 medium, supplemented with $10 \%$ fetal bovine serum and $1 \%$ antibiotic, kept in an oven at $37^{\circ} \mathrm{C}$ and $5 \% \mathrm{CO}_{2}$ atmosphere. The samples were diluted in pure sterile dimethyl sulfoxide (DMSO) and were tested in a single concentration of $25 \mu \mathrm{g}$ $\mathrm{mL}^{-1}$. Statistical analysis of the experiments was performed according to the mean and standard error of the mean (SEM) of the percentage of cell growth inhibition, using the GraphPad Prism 7.00 program (GraphPad).

Compounds which had a percentage of inhibition of tumor growth greater than $75 \%$ in at least one tumor line tested were tested again by serial dilution (dilution factor $=2$ ), starting from the highest $25 \mu \mathrm{g} \mathrm{mL}{ }^{-1}$ concentration for determination of concentration capable of inhibiting 50\% of cell proliferation $\left(\mathrm{IC}_{50}\right)$. The experiments were analyzed by a non-linear regression curve for the calculation of $\mathrm{IC}_{50}$ using the GraphPad Prism program. Doxorubicin was used as a positive control.

\section{Results and discussion}

\section{Synthesis}

2' $N$-phenylsulfonylacetophenone (1) was obtained from the reaction of benzenesulfonyl chloride and 2aminoacetophenone in dichloromethane as previously described (de Castro et al. 2016; de Castro et al. 2017; d'Oliveira et al. 2018). Compounds $\mathbf{2}$ and $\mathbf{3}$ and $\mathbf{4}$ were synthesized by base-catalyzed Claisen-Schmidt condensation between $\mathbf{1}$ and the respective substituted benzaldehyde (Scheme 1). Structure of compounds $\mathbf{2}$ and $\mathbf{4}$ were verified by their ${ }^{1} \mathrm{H}$ NMR spectra.

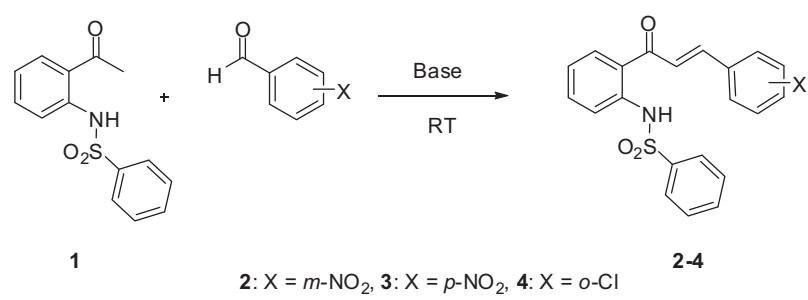

Scheme 1 General conditions for the synthesis of chalcones $\mathbf{2 - 4}$ 
Scheme 2 Synthesis of chalcone-quinolinone compounds 5 and $\mathbf{6}$
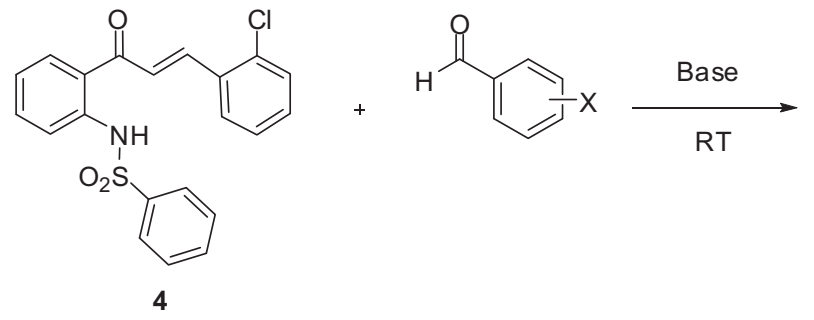

5: $\mathrm{X}=m-\mathrm{NO}_{2}, \mathbf{6}: \mathrm{X}=p-\mathrm{NO}_{2}$

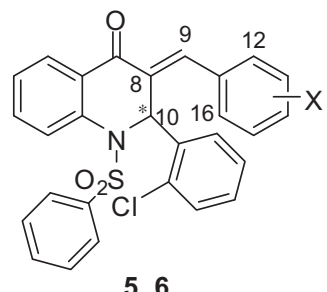

5,6

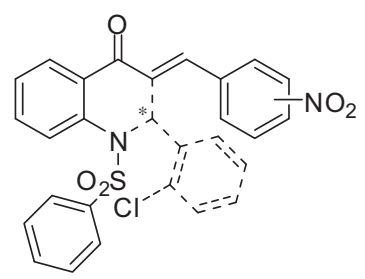

$2,3,5,6$

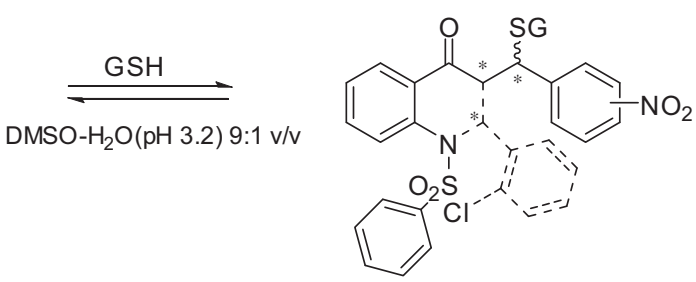

GS-2, GS-3, GS-5, GS-6
Scheme 3 Conjugation reaction of compounds $2, \mathbf{3}, 5$ and $\mathbf{6}$ with GSH retention times: GS-2 a1: 10.3, GS-2 a2: 10.6, 2: 20.0; GS3 a1: 11.0, GS-3 a1: 11.2, 3: 19.7; GS-5 a1: 16.1, GS-5 a2: 16.3, GS-5 b1: 17.7, GS-5 b2: 17.9, 5: 22.2; GS-6 a1: 17.4, GS-6 a2: 17.6, GS-6 b1: 18.5, GS-6 b2: 18.6, 6: 22.8 . Figures 2 and 3 illustrate the analyses of compounds 2 and $\mathbf{5}$, respectively.

The occurrence of the conjugation reactions was confirmed by LC-ESI-MS analysis for each peak observed in the chromatograms. Figures 2 and 3 illustrate the results for compounds $\mathbf{2}$ and $\mathbf{5}$, respectively. Besides the deprotonated and protonated molecules of each precursor $\left([\mathrm{M}-\mathrm{H}]^{-}\right.$for compounds 2 and $\mathbf{3},[\mathrm{M}+\mathrm{H}]^{+}$for compounds 5 and $\mathbf{6}$ ), ESI-MS analysis of each incubation confirmed the presence of the respective GSH conjugates. These latter showed the following ions attributed to the respective deprotonated and protonated molecules: GS-2 a1 and $\mathbf{a} 2$ at $\mathrm{m} / \mathrm{z} 714[\mathbf{M}-\mathbf{H}]^{-}$, GS-3 a1 and a2 $\mathrm{m} / \mathrm{z} 714[\mathrm{M}-\mathrm{H}]^{-}$, GS-5 a1, a2, b1 and b2 at $\mathrm{m} / \mathrm{z} 838\left[\mathrm{MH}^{+}\right]$and GS-6 a1, a2, b1 and b2 at $\mathrm{m} / \mathrm{z} 838$ $\left[\mathrm{MH}^{+}\right]$(accurate masses and mass errors relative to expected $\mathrm{m} / \mathrm{z}$ values calculated from elemental compositions are given in Figs. 2 and 3). GSH conjugates also displayed characteristic ion fragmentation in the ESI source of the instrument, while the chalcones $(\mathbf{2}, \mathbf{3})$ and the quinolinone-chalcone hybrids $(\mathbf{5}, \mathbf{6})$ required CID to produce structure-related fragment ions for MS/MS analysis. The respective mass spectra of compounds $\mathbf{3}$ and $\mathbf{6}$ can be found in Figure S19 and Figure S20 of the Supplementary Data.

It is worth noting that in the chromatograms of the incubates of $\mathbf{5}$ and $\mathbf{6}$ only two pairs of peaks were observed, which might correspond to two pairs of diastereomeric adducts. Such a reduction in the number of the formed diastereomers can be explained by the selective formation 
A

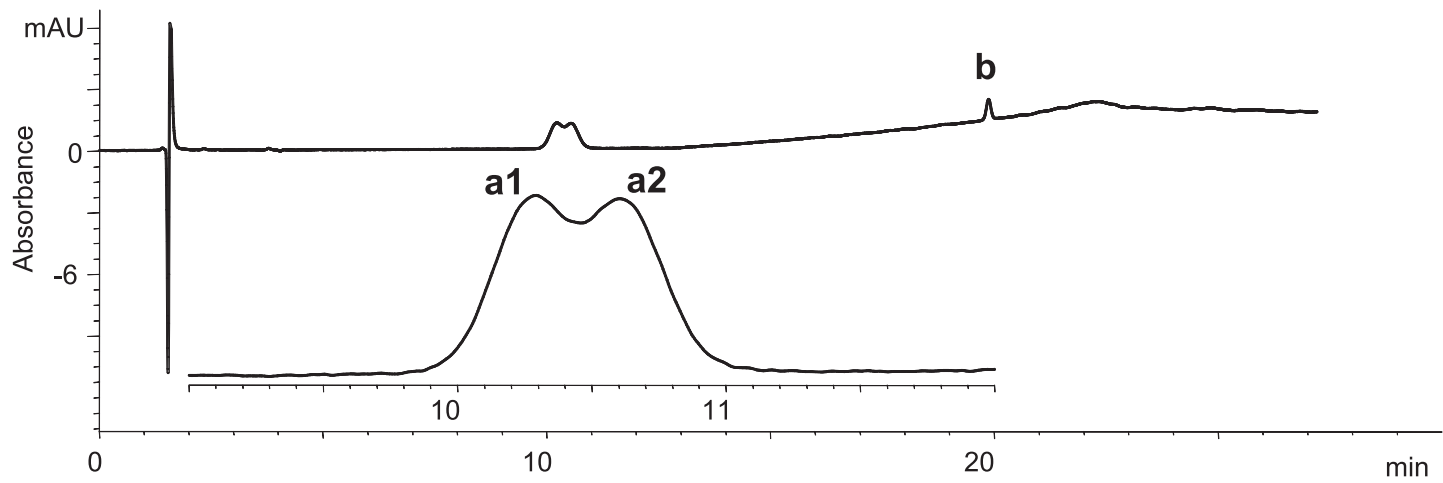

B
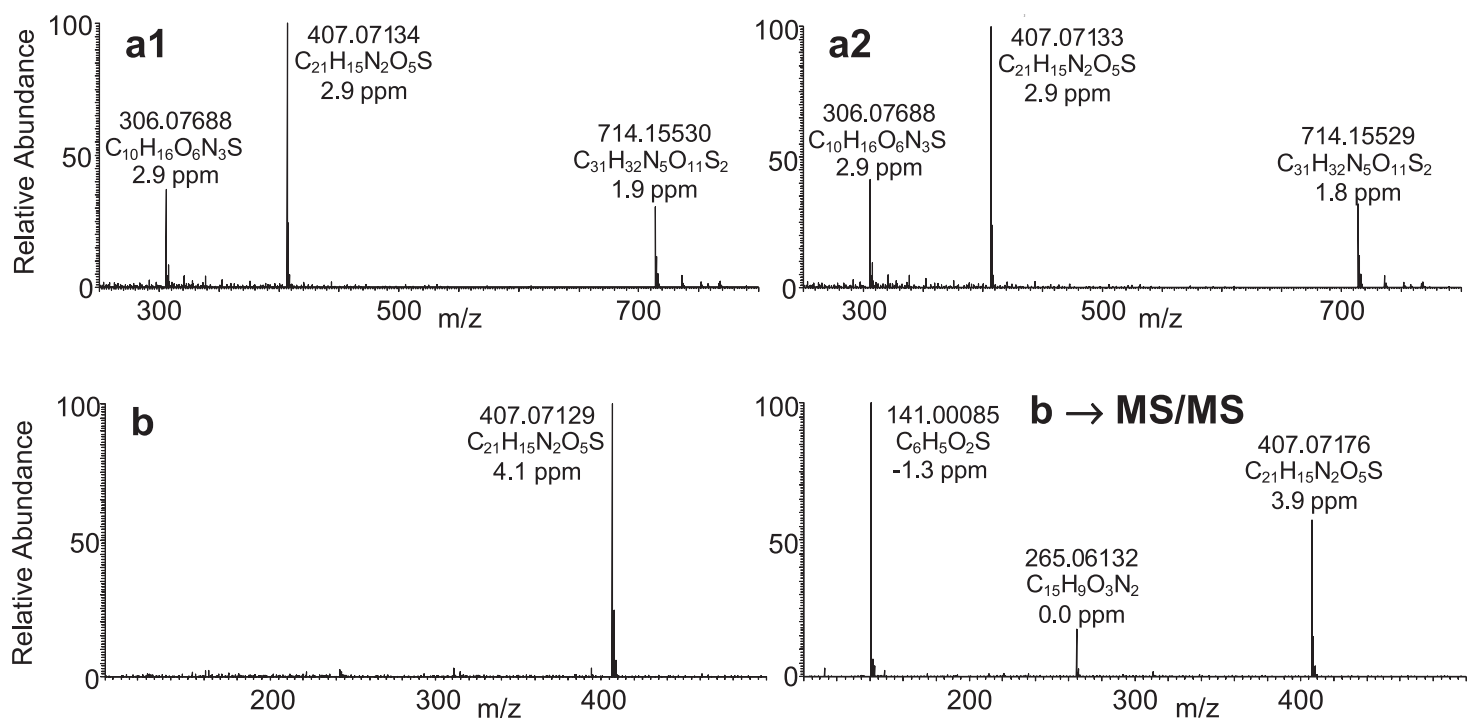

Fig. 2 a HPLC analysis of the mixture of 2 and their GSH conjugates, along with (b) negative-ion ESI mass spectra of a1 and a2 diastereomers of the GS-2 conjugates and negative-ion ESI mass spectra and

MS/MS of 2 (b) obtained by LC-ESI-MS analyses. Assays were performed with the 10-min incubation sample of compound 2 using $7.5 \mathrm{mmol} \mathrm{L}^{-1}$ initial GSH concentration

of the trans diastereomers because of the conformationally restricted orientation of the bulk C10-aryl group (see Scheme 2). Thiol addition onto the oxygen-counterpart 2phenyl- $(E)$-3-benzylidene-chroman-4-ones also resulted in the formation of the corresponding trans adducts with respect to the C8-C10 H-atoms (Osama et al. 2014) However, determination of the exact stereochemistry of the formed adducts needs further synthetic and analytical experiments.

The employed HPLC-UV conditions of analysis of the incubates allowed to determine the amount of the remaining chalcones as a function of the incubation time. Figure 4 shows typical chromatograms of these incubations. The retention times of compounds $\mathbf{2}, \mathbf{3}, \mathbf{5}$ and $\mathbf{6}$ are 3.3, 3.2, 4.3 and $5.0 \mathrm{~min}$, respectively. Although close to the dead volume, it was also possible to detect the diastereomeric peaks of the GSH conjugates.
Figures 5 and 6 show the concentration of the remaining chalcones as a function of incubation times at a higher (upper graph) and a lower (lower graph) GSH concentration. In the equilibrium mixtures of the higher $\left(7.5 \mathrm{mmol} \mathrm{L}^{-1}\right)$ and the lower $\left(1.875 \mathrm{mmol} \mathrm{L}^{-1}\right) \mathrm{GSH}$ concentration, the amount of the unreacted chalcone $\mathbf{2}$ and $\mathbf{3}$ was near 3 and $10 \%$ of the initial value, respectively. On the other hand, much higher amount of unreacted quinolinone-chalcones could be detected in the equilibrium mixtures of compounds $\mathbf{5}$ and $\mathbf{6}$ (reacting under the same conditions): compound 5: $72 \%$ (higher concentration of GSH) and 92\% (lower concentration of GSH); compound 6: $77 \%$ (higher concentration of $\mathrm{GSH}$ ) and 93\% (lower concentration of GSH).

The results indicate that all four compounds reach the equilibrium conditions in a relatively short time. The amounts of the formed GSH-conjugates at equilibrium are much higher in the case of the sulfonamide chalcones ( 2 and 

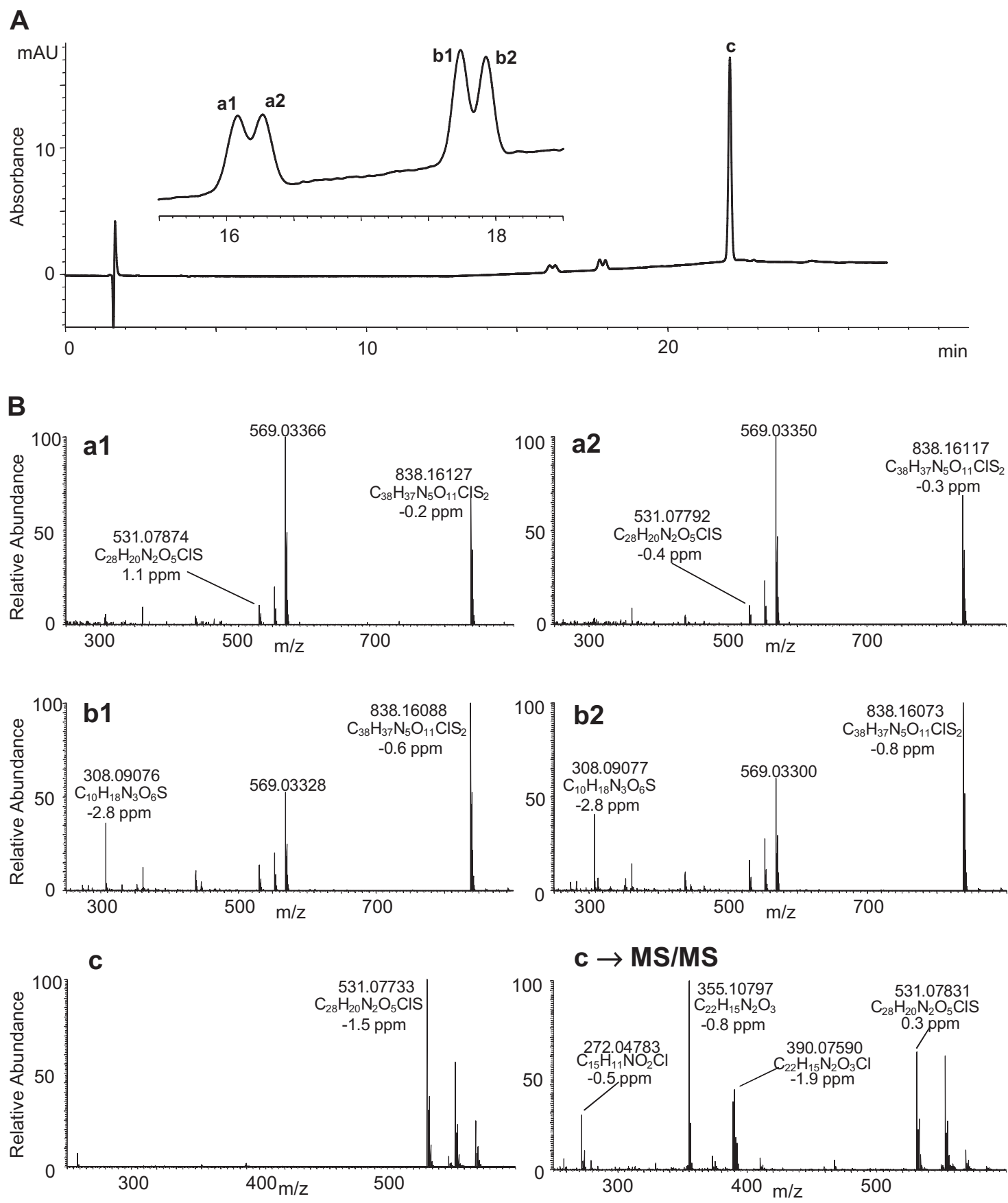

$\mathrm{c} \rightarrow \mathrm{MS} / \mathrm{MS}$

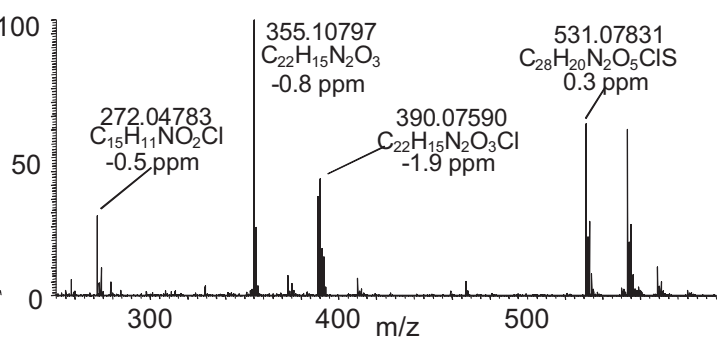

Fig. 3 a HPLC analysis of the mixture of $\mathbf{5}$ and their GSH conjugates, along with (b) positive-ion ESI mass spectra of a1, a2, b1 and b2 diastereomers of the GS-5 conjugates and positive-ion ESI mass

spectra and MS/MS of 5 (c) obtained by LC-ESI-MS analyses. Assays were performed with the 10-min incubation sample of compound $\mathbf{5}$ using $7.5 \mathrm{mmol} \mathrm{L}^{-1}$ initial GSH concentration

3) than for the cyclic quinolinone-chalcones (5 and $\mathbf{6})$. The initial GSH:chalcone ratio has limited influence on the composition of the equilibriums. Accordingly, the equilibrium is thermodynamically controlled, and the time needed to reach the equilibrium is determined by the rates of the forward and the backward reactions.

As a model, the kinetic rate law for second- and firstorder reversible reactions (Lavabre et al. 1993) was

considered:

$$
A+B \rightleftharpoons C \quad v=k_{1}[\mathrm{~A}][\mathrm{B}]-k_{2}[\mathrm{C}]
$$

The velocity (v) in Eq. (1) of the cited publication is a function of $k_{l}$ (forward reaction), $k_{2}$ (reverse reaction) and $t$ (time). Using data from 0 to $4 \mathrm{~min}$ from the reactions with the higher $\left(7.5 \mathrm{mmol} \mathrm{L}^{-1}\right) \mathrm{GSH}$ concentration, $k_{1}$ and $k_{2}$ were obtained through curve fitting and given in Table 1. 

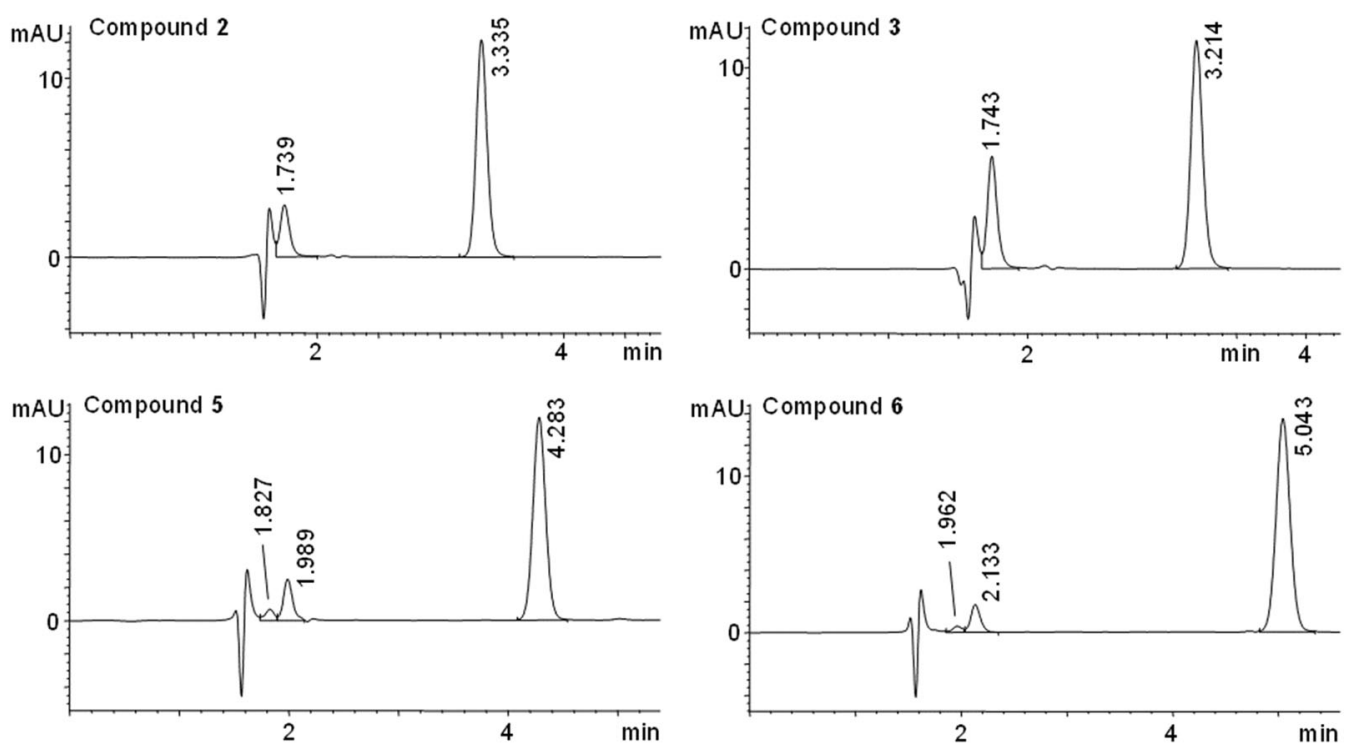

Fig. 4 Typical HPLC-UV chromatograms of incubations of compounds 2, 3, 5 and 6

Remaining precursor chalcones 2 and 3 at the higher GSH concentration

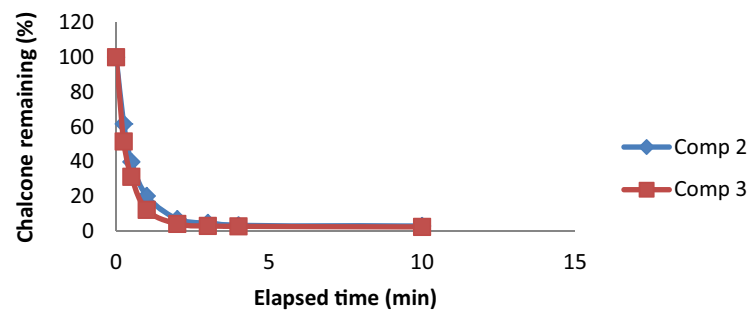

Remaining precursor chalcones $\mathbf{2}$ and $\mathbf{3}$ at the lower GSH concentration

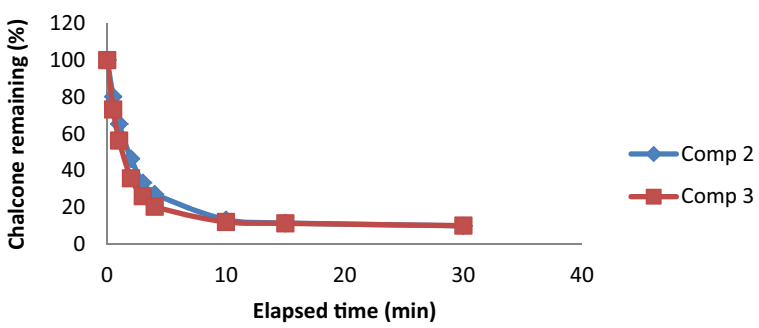

Fig. 5 Remaining percentage chalcone versus time of incubation for compounds 2 and 3: Reactions in DMSO: $\mathrm{H}_{2} \mathrm{O}(9: 1 \mathrm{v} / \mathrm{v})$ at higher $\left(7.5 \mathrm{mmol} \mathrm{L}^{-1}\right)$ and lower $\left(1.875 \mathrm{mmol} \mathrm{L}^{-1}\right) \mathrm{GSH}$ concentration

The difference between the values of $k_{1}$ for the compounds $\mathbf{2}$ and $\mathbf{3}$ may be rationalized by the strong electron withdrawing effect of the para-nitro group, which decreases the electron density of the $\beta$-carbon, making the nucleophilic attack of the GSH thiol group easier. On the contrary, a different pattern has been observed on comparison of the $k_{l}$ values of compounds 5 and $\mathbf{6}$. In this case, it can be supposed that, due to the non-planar structure of the enone moiety, transmission of the para-nitro group's effect is not
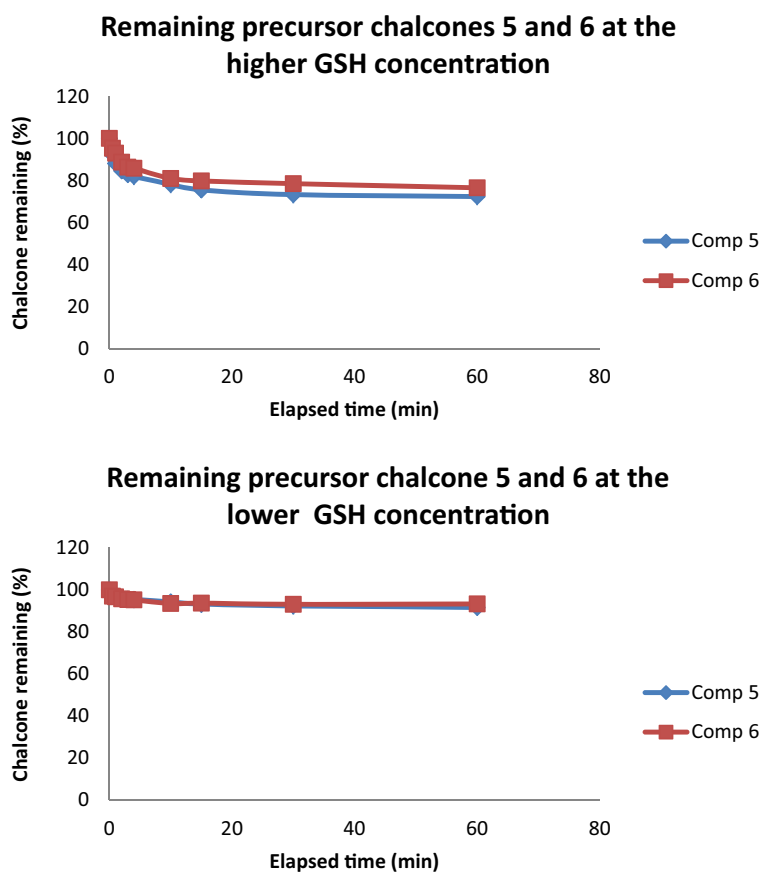

Fig. 6 Remaining percentage chalcone versus time of incubation for compounds 5 and 6: Reactions in DMSO: $\mathrm{H}_{2} \mathrm{O}(9: 1 \mathrm{v} / \mathrm{v})$ at higher $\left(7.5 \mathrm{mmol} \mathrm{L}^{-1}\right)$ and lower $\left(1.875 \mathrm{mmol} \mathrm{L}^{-1}\right) \mathrm{GSH}$ concentration

Table 1 Calculated $k_{1}$ and $k_{2}$ using the kinetic model of equilibria (1)

\begin{tabular}{lllll}
\hline Compound & 2 & 3 & 5 & 6 \\
\hline$k_{l}$ & 127.5 & 171.4 & 26.1 & 13.4 \\
$k_{2}$ & 0.025 & 0.034 & 0.880 & 0.536 \\
\hline
\end{tabular}

so effective, and the inductive effect of the meta-nitro group reduces the electron density of the $\beta$-carbon atom more 
profoundly. Comparison of the differences of the $k_{l}$ values of compounds $\mathbf{2}$ and $\mathbf{3}$ to those of $\mathbf{5}$ and $\mathbf{6}$ can justify the difference in the times needed to reach the equilibrium of the two sets of chalcone derivatives.

These findings allowed us to make two conclusions. First, it is possible to change the structure of the highly thiol-reactive chalcones ( 2 and $\mathbf{3}$ ) and convert the molecules into moderately (5-15-times) less reactive derivatives such as the quinolinones $\mathbf{5}$ and $\mathbf{6}$. Second, as a consequence of the somewhat reduced thiol-reactivity and, moreover, more profoundly (15-35-times) reduced stability of the resultant GSH adducts, derivatives (5 and $\mathbf{6}$ ) may not reduce cellular GSH as much as the corresponding open-chain chalcones (2 and 3). According to the conclusions drawn from earlier studies (Dinkova-Kostova et al. 2001; Jin et al. 2008) the quinolinone-chalcone hybrids ( $\mathbf{5}$ and $\mathbf{6}$ ) would be expected therefore to show lower antitumor effect than that of the open-chain chalcones ( 2 and $\mathbf{3}$ ).

The above reactions were performed in a basically polar non-protic medium (DMSO with $10 \% \mathrm{H}_{2} \mathrm{O}$ ) due to the poor solubility of the chalcones in polar protic solvents. To investigate how the reverse reaction might proceed in a protic medium (mimicking physiological conditions), the reverse reaction was studied in a methanol/water $(75: 25 \mathrm{v} / \mathrm{v})$ mixture. Figure 7 shows the amount of the remaining GSHadduct as a function of time, indirectly determined by measuring the amount of the respective precursor chalcone $(2,3,5$ and $\mathbf{6})$.

As the results shown in Fig. 7 demonstrate, the rate of decomposition (retro-Michael reaction) of the open-chain chalcone-GSH conjugates (GS-2 and GS-3) is very slow confirming the results presented in Table 1. On the contrary, the rate of the reverse reaction of the cyclic quinolinonechalcone-GSH adducts (GS-5 and GS-6) is much faster. Similar results were obtained in the experiments performed in the DMSO- $\mathrm{H}_{2} \mathrm{O}(90: 10 \mathrm{v} / \mathrm{v})$ mixture.

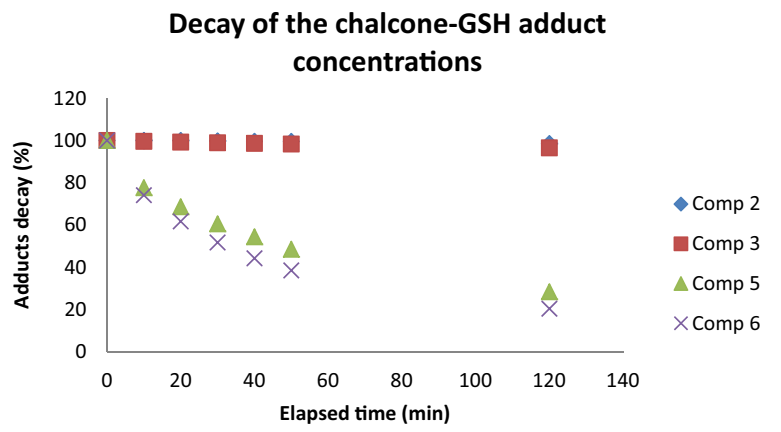

Fig. 7 Decay of the GSH-adduct of chalcones $2,3,5$ and 6 (GS-2, GS3, GS-5 and GS-6, respectively) in a methanol/water $(75: 25 \mathrm{v} / \mathrm{v})$ mixture

\section{Structural and theoretical analysis}

To provide explanations on how the molecular structure could affect this non-enzyme catalyzed nucleophilic addition, crystal structures of compounds $\mathbf{2}$ and $\mathbf{5}$ were obtained from single crystal X-ray diffraction. Both $\mathbf{2}$ and $\mathbf{5}$ have crystallized under monoclinic centrosymmetric space group P $2 / 1$ c. The crystallographic refinement of $\mathbf{2}$ led to a model with $R_{l}=5.27 \%$ and Goof $=1.045$ and the model proposed for 5 has $R_{1}=6.21 \%$ and $G o o f=1.054$. An Ortep representation (Farrugia 2012) showing the thermic atomic displacements of both compounds is given in Fig. 8 .

As it is shown in Fig. 9, some characteristic differences can be noted between the crystal structures of compounds 2 (represented by blue color) and $\mathbf{5}$ (represented by cyan color) as a result of the cyclization reaction. It was found that the sulfonyl group adopts a -syn-periplanar conformation regarding the carbonyl group $(\llcorner\mathrm{N} 2-\mathrm{C} 15-\mathrm{C} 9-\mathrm{O} 1=$ $-3.72^{\circ}$ ) in compound 2 , while a + anti-periplanar one $\left(\left\llcorner\mathrm{N} 2-\mathrm{C} 10-\mathrm{C} 12-\mathrm{O} 1=168.07^{\circ}\right)\right.$ in compound 5 . This different conformation of compound $\mathbf{5}$ is the result of rotation of the aromatic ring of the benzylidene moiety and contributes to a steric hindrance of the $\beta$-carbon atom (the GSH reaction site). The presence of the chlorophenyl group in compound $\mathbf{5}$ also contributes to steric hindrance, which corroborates explanation its lower $k_{l}$ in comparison to compound 2 (see Table 1).

The planarity of $\mathbf{2}$ and $\mathbf{5}$ can be evaluated from the chalcone backbone. In $\mathbf{2}$, this moiety can be considered planar, since the nitro group has a torsion close to $180^{\circ}$ regarding the olefin portion ( + anti-periplanar conformation, with $\left\llcorner\mathrm{C} 8-\mathrm{C} 7-\mathrm{C} 2-\mathrm{N} 1=176.51^{\circ}\right)$. In contrast, deviation from planarity of the chalcone moiety of $\mathbf{5}$ is confirmed by analyzing this same dihedral angle, which is for a -synclinal conformation $\left(\left\llcorner\mathrm{C} 8-\mathrm{C} 7-\mathrm{C} 2-\mathrm{N} 1=-36.80^{\circ}\right)\right.$. Because of this planarity deviation, $\mathbf{2}$ is more stabilized by conjugation than $\mathbf{5}$. In addition, since the GSH-reaction is a nucleophilic addition, positive charges close to the $\beta$-carbon contributes to $k_{l}$. Accordingly, the higher $k_{l}$ for compound 2 is also explained by the presence of the $\alpha$-proton (to the carbonyl group), which is missing in compound $\mathbf{5}$.

Theoretical calculations also were performed to explain the trend of $k_{l}$ values from Table 1. In Fig. 10, the shape and the energies of the highest occupied molecular orbital (HOMO) and the lowest unoccupied molecular orbital (LUMO) of the studied compounds are shown. The HOMO indicates the regions where the molecule acts as an electron donor, while LUMO indicates the acceptor regions. For 2, the LUMO is close only to the chalcone backbone and has the energy of $\mathrm{E}_{\mathrm{LUMO}}=-3.19 \mathrm{eV}$, and the HOMO is concentrated on both the benzenesulphonyl group and the ring nitrogen with the energy of $\mathrm{E}_{\mathrm{HOMO}}=-6.88 \mathrm{eV}$. Similar to $\mathbf{2}$, the LUMO of compound $\mathbf{5}$ is also over the chalcone 


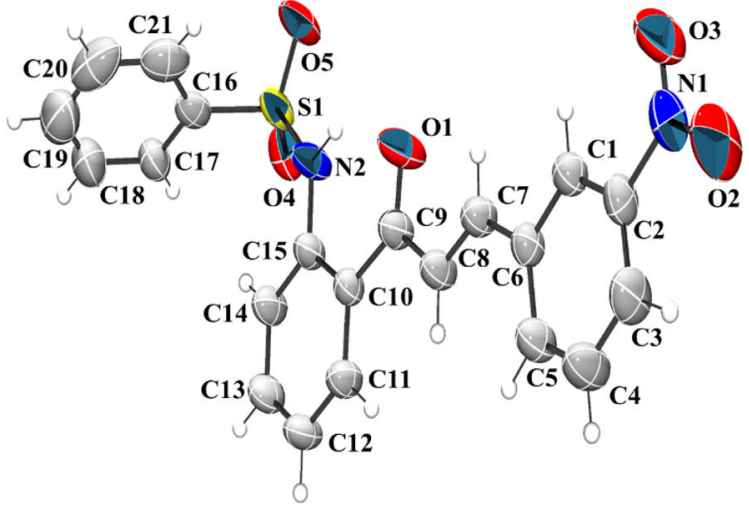

(a)

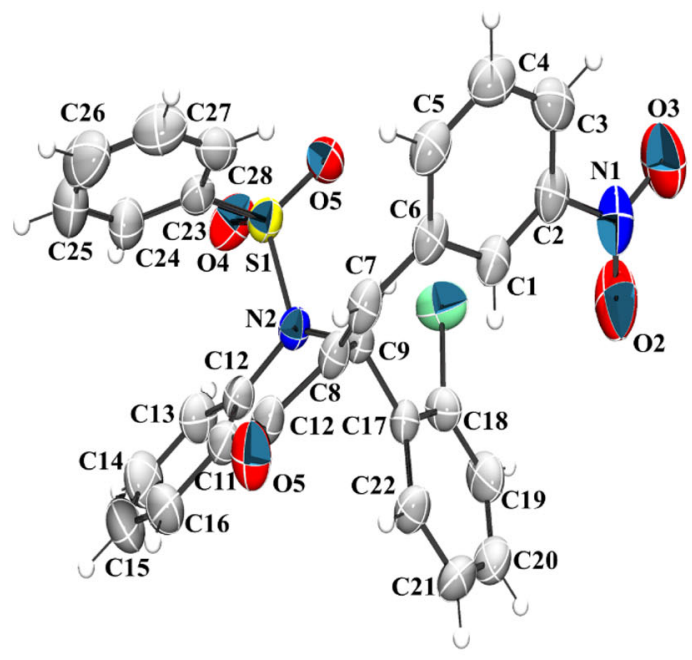

(b)

Fig. 8 Ortep representation showing the thermal displacement of 2 (a) and 5 (b) with 50\% probability. Hydrogens displayed as spheres with arbitrary radii

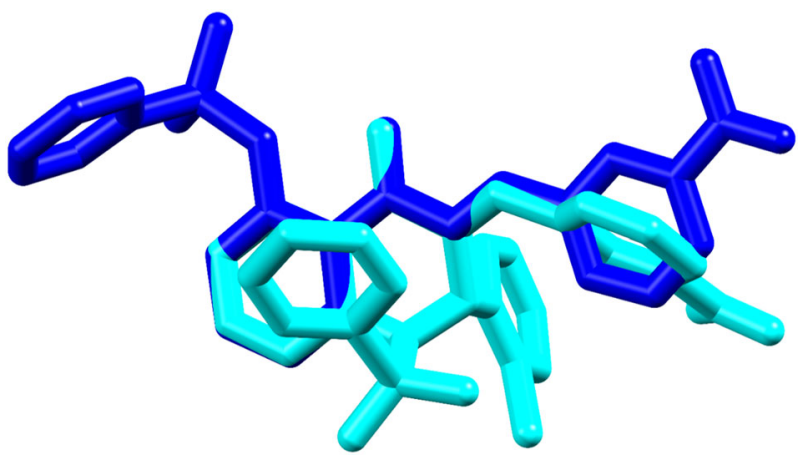

Fig. 9 Overlapping of crystal structures of 2 (represented by blue color) and $\mathbf{5}$ (represented by cyan color) showing the main differences between them. The aromatic ring closer to carbonyl group was used as a fixed point

backbone, but with higher energy $\left(\mathrm{E}_{\mathrm{LUMO}}=-2.96 \mathrm{eV}\right)$, while the HOMO is mostly spread over the chlorobenzene group $\left(\mathrm{E}_{\mathrm{HOMO}}=-6.93 \mathrm{eV}\right)$. This difference of HOMO and LUMO energies implies a lower gap energy for compound 2 $\left(\mathrm{E}_{\mathrm{GAP}}=3.69 \mathrm{eV}\right)$, indicating a higher reaction susceptibility.

Molecular electrostatic potential surfaces of $\mathbf{2}$ and $\mathbf{5}$ are presented in Fig. 11. This surface is an electron density map that also indicates the donor regions (represented by blue color) and the acceptor regions (represented by red color). Lower energies are found over the sulfonyl and the nitro group $\left(\delta^{-} \approx-1.47 \mathrm{eV}\right.$ for 2 and $\delta^{-} \approx 1.42 \mathrm{eV}$ for $\mathbf{5}$ ), while higher energies are concentrated close to the olefin portion and the $\beta$-carbon $\left(\delta^{+} \approx 1.33 \mathrm{eV}\right.$ for 2 and $\delta^{+} \approx 0.61 \mathrm{eV}$ for 5). In addition, theoretical calculations indicated a positive partial charge on the $\beta$-carbon of compound $2\left(\delta^{+}=\right.$ $3.92 \mathrm{eV}$ ), which contributes to the GSH addition reaction, and negative partial charge on $\beta$-carbon from compound $\mathbf{5}$ $\left(\delta^{-}=5.89 \mathrm{eV}\right)$, which contributes to $\mathrm{GSH}$ elimination reaction.

\section{Antitumor potency}

Cytotoxicity of the compounds has been tested by means of the universally used MTT method (Skehan et al. 1980). The results of the cytotoxicity testing of compounds $2, \mathbf{3}, \mathbf{5}$ and 6 against PC-3 (prostate), HCT-116 (colon) and SF-295 (glioblastoma) human tumor cell lines are shown in Table 2.

Among the tested compounds, 2, 3 and $\mathbf{6}$ were considered to be cytotoxic with a percentage of inhibition of tumor growth in some cell line greater than $75 \%$ (taking in account the standard deviations). Table 3 presents the $\mathrm{IC}_{50}$ values of the tested compounds.

As it is shown, it was not possible to find an unambiguous correlation in the ring substitution of $\mathbf{2}$ to $\mathbf{3}$ or $\mathbf{5}$ to $\mathbf{6}$, and their antitumor activity. Specifically, compound $\mathbf{2}$ (meta-substituted) showed higher potency towards PC3 and HTC-116, and lower to SF-295, comparing it with compound 3 (para-substituted). In turn, compound 5 (metasubstituted) showed higher potency to inhibit tumor growth of SF-295 cells, and lower one of the PC3 and HTC-116 cells in comparison with compound $\mathbf{6}$ (para-substituted). The average inhibition of the chalcones $\mathbf{2}$ and $\mathbf{3}$ was $60 \%$, while the average inhibition of the chalcone-quinolinones $\mathbf{5}$ and 6 was $62 \%$. Therefore, although GSH-reactivity of compounds $\mathbf{5}$ and $\mathbf{6}$ was considerably lower than that of $\mathbf{2}$ and $\mathbf{3}$ (as shown in Table 1), the average inhibition of tumor growth of the compounds was similar.

The results suggest that conjugation with GSH or with other SH-reactive cellular thiols is not a determining factor in the antitumor activities of the compounds. This is in 

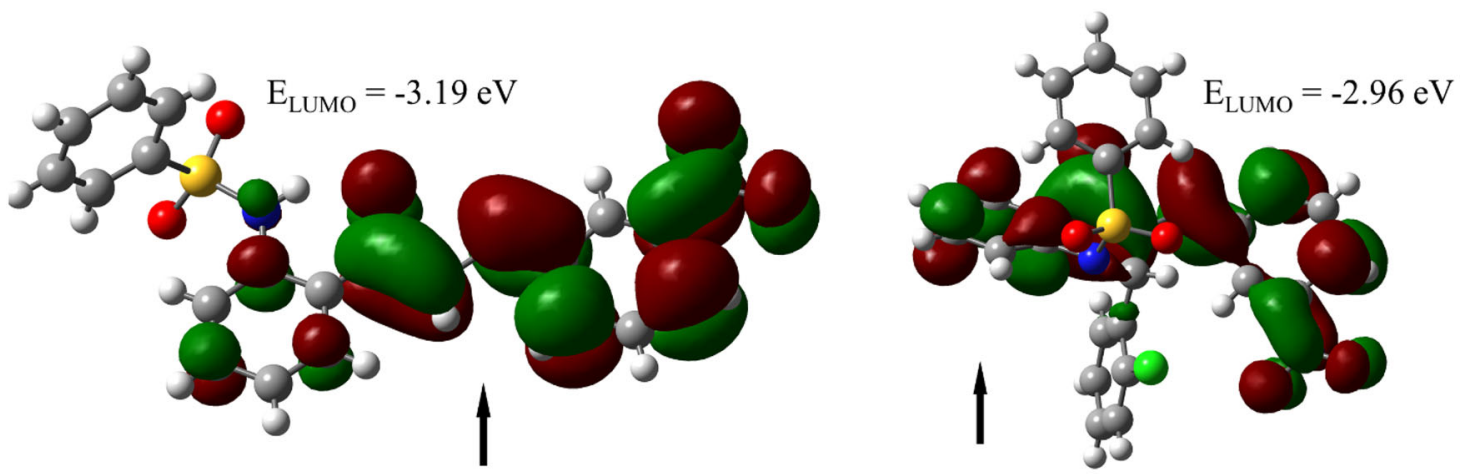

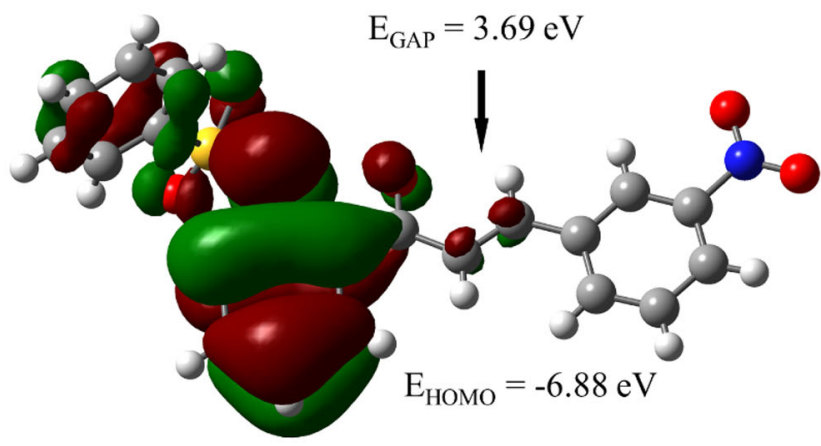

(a)

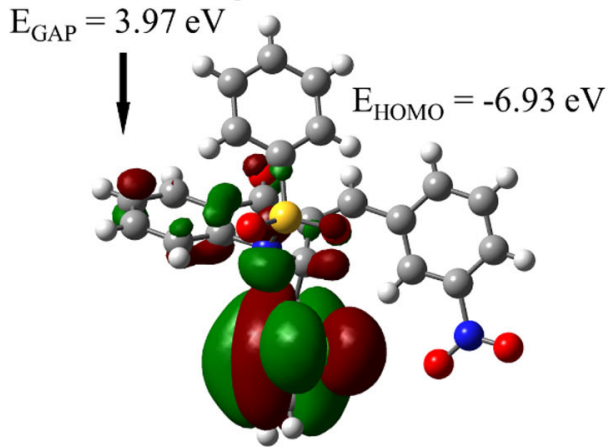

(b)

Fig. 10 Frontier molecular orbitals of compounds 2 (a) and $\mathbf{5}$ (b). Energies (E) of the highest occupied molecular orbital (HOMO) and lowest unoccupied molecular orbital (LUMO) are shown. $\mathrm{E}_{\mathrm{GAP}}$ is the difference between $\mathrm{E}_{\mathrm{LUMO}}$ and $\mathrm{E}_{\mathrm{HOMO}}$

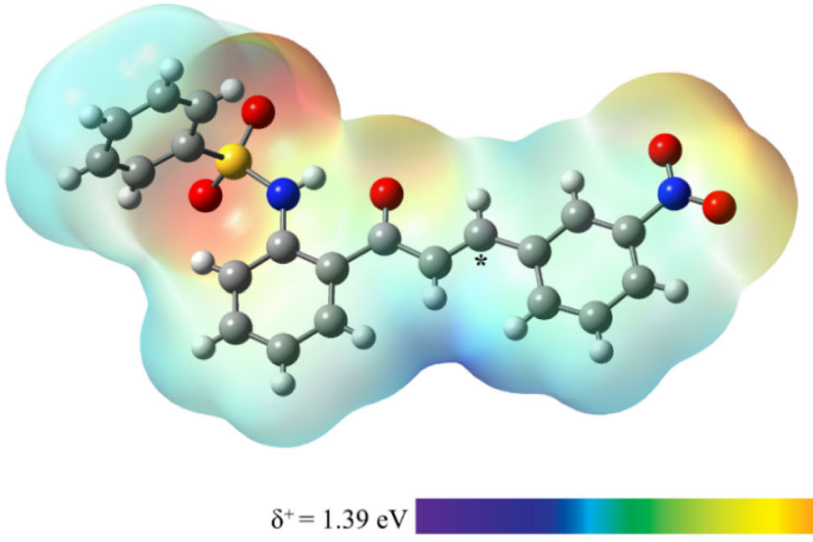

(a)

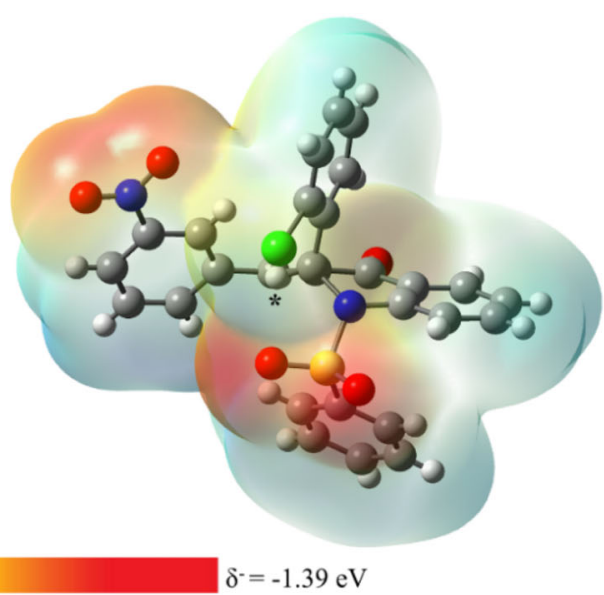

(b)

Fig. 11 Molecular electrostatic potential (MEP) of compounds 2 (a) and 5 (b). In both representations the $\beta$-carbon is marked. Red regions indicate high electron density and blue regions indicate low electron density

agreement with the results of our previous studies with cyclic chalcone analogues. It was found that the derivatives with the highest antitumor activities are those ones with substituents with strong electron-donating character on the benzylidene moiety (Dimmock et al. 1999). Cell cycle analysis of Jurkat-
T cells exposed to the compounds showed a characteristic G2-M block suggesting their microtubule activity (Rozmer et al. 2006). Chalcone-tubulin interaction has been demonstrated in several previous publications (Stanton et al. 2011; Martel-Frachet et al. 2015; Lindamulage et al. 2017). 
Table 2 Percentage inhibition of tumor growth by compounds $\mathbf{2}, \mathbf{3}, \mathbf{5}$ and $\mathbf{6}$ in vitro compared to untreated control at a single concentration of $25 \mu \mathrm{g} \mathrm{mL}^{-1}$ in three human tumor cell lines (PC3, HTC-116 and SF295) after $72 \mathrm{~h}$ of treatment as determined by the MTT method

\begin{tabular}{llll}
\hline Compound & PC3 & HTC-116 & SF-295 \\
\hline $\mathbf{2}$ & $77.9 \pm 3.4$ & $66.8 \pm 0.9^{\mathrm{a}}$ & $63.5 \pm 1.1$ \\
$\mathbf{3}$ & $45.0 \pm 0.2$ & $25.7 \pm 1.4$ & $81.5 \pm 2.5$ \\
$\mathbf{5}$ & $49.6 \pm 1.2$ & $72.8 \pm 0.5^{\mathrm{a}}$ & $60.1 \pm 1.6$ \\
$\mathbf{6}$ & $68.4 \pm 0.3$ & $73.4 \pm 2.4^{\mathrm{a}}$ & $50.1 \pm 2.1$ \\
\hline
\end{tabular}

${ }^{\mathrm{a}}$ From d'Oliveira et al. (2018)

Table $3 \mathrm{IC}_{50}\left(\mu \mathrm{g} \mathrm{mL}^{-1}\right)$ values (with $95 \%$ confidence intervals in parentheses) for compounds 2,3 and $\mathbf{6}$ in tumor cell lines after $72 \mathrm{~h}$ of treatment, as determined by the MTT method

\begin{tabular}{llll}
\hline Entry & PC3 & HTC-116 & SF-295 \\
\hline $\mathbf{2}$ & $7.9(6.5-9.7)$ & $6.6(5.7-7.5)$ & $6.9(6.3-7.7)$ \\
$\mathbf{3}$ & $>25$ & $>25$ & $11.5(9.6-13.8)$ \\
$\mathbf{6}$ & $>25$ & $19.3(13.7-27.2)^{\mathrm{a}}$ & $>25$ \\
Doxorubicin & $0.44(0.34-0.54)$ & $0.12(0.09-0.17)$ & $0.24(0.2-0.27)$ \\
\hline
\end{tabular}

${ }^{a}$ From d'Oliveira et al. (2018)

\section{Conclusion}

It was shown that it is possible to substantially change equilibrium composition of the reaction of the same chalcone moiety with GSH by making a structural hybrid with a quinolinone moiety. This structural modification not only reduced thiol reactivity, but also decreased chemical stability of the formed GSH-adducts of the compounds. On the other hand, these structural differences did not influence the biological activity of the compounds; antitumor potencies remained unchanged despite the very different equilibrium compositions of the chalcone-GSH incubates under the investigated conditions. Overall, the present results support a non-thiol reactivity-based biological action of the investigated chalcone derivatives.

Acknowledgements Open access funding provided by University of Pécs (PTE). The authors express their special thanks to Coordenadoria de Aperfeiçoamento de Pessoal de Ensino Superior (CAPES) (Grant No. 88881.134665/2016-01) for a fellowship (to Giulio Demetrius Creazzo d'Oliveira) for supporting this work. The authors express their sincere thanks to the EFOP Operational Program (Grant No. EFOP3.6.1-16-2016-00004) (to Pál Perjési) and the Conselho Nacional de Desenvolvimento Científico Tecnológico (CNPq) (Grant No. 478337/ 2013-2) (to Caridad Noda Perez) for providing financial support. The Robert A. Welch Foundation also is kindly acknowledged (for endowment BK-0031 to Laszlo Prokai).

\section{Compliance with ethical standards}

Conflict of interest The authors declare that they have no conflict of interest.
Publisher's note: Springer Nature remains neutral with regard to jurisdictional claims in published maps and institutional affiliations.

Open Access This article is distributed under the terms of the Creative Commons Attribution 4.0 International License (http://crea tivecommons.org/licenses/by/4.0/), which permits unrestricted use, distribution, and reproduction in any medium, provided you give appropriate credit to the original author(s) and the source, provide a link to the Creative Commons license, and indicate if changes were made.

\section{References}

Amslinger S (2010) The tunable functionality of $\alpha, \beta$-unsaturated carbonyl compounds enable their differential application in biological systems. ChemMedChem 5:351-356

Bansal A, Simon MC (2018) Glutathione metabolism in cancer progression and treatment resistance. J Cell Biol. 217:2291-2298

Bernardes A, d'Oliveira GDC, Silezin A, Kuzma M, Molnár S, Pérez CN, Perjési P (2018) Reagent-induced asymmetric induction in addition reaction of reduced glutathione onto bis-Mannich chalcones. Arch Pharm 351:1700386. https://doi.org/10.1002/ardp. 201700386

Bernardes A, Pérez CN, Mayer M, Da Silva CC, Martins FT, Perjési P (2017) Study of reactions of two Mannich bases derived of 4'hydroxychalcones with glutathione by RP-TLC, RP-HPLC and RP-HPLC-ESI-MS analysis. J Braz Chem Soc 28:1048-1062

Berridge MV, Tan AS, McCoy KD, Wang R (1996) The biochemical and cellular basis of cell proliferation assays that use tetrazolium salts. Biochemica 4:14-19.

de Castro MRC, Aragão AQ, da Silva CC, Pérez CN, Queiroz DPK, Queiroz Jr LHK, Barreto S, de Moraes MO, Martins FT (2016) Conformational variability in sulfonamide chalcone hybrids: crystal structure and cytotoxicity. J Braz Chem Soc 27:884-898

de Castro MRC, Naves RF, Bernardes A, da Silva CC, Pérez CN, Moura AF, de Moraes MO, Martins FT (2017) Tandem chalconesulfonamide hybridization, cyclization and further ClaisenSchmidt condensation: Tuning molecular diversity through reaction time and order and catalyst. Arab J Chem. https://doi.org/ 10.1016/j.arabjc.2017.11.005

Dimmock JR, Kandepu NM, Nazarali AJ, Kowalchuk TP, Motaganahalli N, Quail JW, Mykytiuk P, Audette GF, Prasad L, Perjési P, Allen TM, Santos CL, Szydlowski J, De Clercq E, Balzarini J (1999) Conformational and quantitative structure-activity relationship study of cytotoxic 2-arylidenebenzocycloalkanones. J Med Chem 42:1358-1366

Dinkova-Kostova AT, Massiah MA, Bozak RE, Hicks RJ, Talalay P (2001) Potency of Michael reaction acceptors as inducers of enzymes that protect against carcinogenesis depends on their reactivity with sulfhydryl groups. Proc Natl Acad Sci USA 98:3404-3409

d'Oliverira GDC, Moura AF, de Moraes MO, Pérez CN, Liao LM (2018) Synthesis, characterization and evaluation of in vivo antitumor activities of novel chalcone-quinolinone hybrid compounds. J Braz Chem Soc 29:2308-2325

Estrela JM, Ortega A, Obrador E (2006) Glutathione in cancer biology and therapy. Crit Rev Clin Labor Sci. 43:143-181

Farrugia LJ (2012) WinGX and ORTEP for Windows: an update. J Appl Crystallogr. 45:849-854

Frisch MJ, Trucks GW, Schlegel HB, Scuseria GE, Robb MA, Cheeseman JR, Scalmani G, Barone V, Mennucci B, Petersson GA, Nakatsuji H, Caricato M, Li X, Hratchian HP, Izmaylov AF, Bloino Zheng JG, Sonnenberg JL, Hada M, Ehara M, Toyota K, Fukuda R, Hasegawa J, Ishida M, Nakajima T, Honda Y, Kitao 
O, Nakai H, Vreven T, Montgomery Jr JA, Peralta JE, Ogliaro F, Bearpark M, Heyd JJ, Brothers E, Kudin KN, Staroverov VN, Kobayashi R, Normand J, Raghavachari K, Rendell A, Burant JC, Iyengar SS, Tomasi J, Cossi M, Rega N, Millam JM, Klene M, Knox JE, Cross JB, Bakken V, Adamo C, Jaramillo J, Gomperts R, Stratmann RE, Yazyev O, Austin AJ, Cammi R, Pomelli C, Ochterski JW, Martin RL, Morokuma K, Zakrzewski VG, Voth GA, Salvador P, Dannenberg JJ, Dapprich S, Daniels AD, Farkas Ö, Foresman JB, J. Ortiz V, Cioslowski J, Fox DJ (2009) Gaussian 09, Revision A.02. Gaussian Inc, Wallingford CT

Go ML, Wu X, Liu XL (2005) Chalcones: an update on cytotoxic and chemoprotective properties. Curr Med Chem 12:481-499

Gomes MN, Muratov EN, Pereira M, Peixoto JC, Rosseto LP, Cravo PVL, Andrade CH, Neves BJ (2017) Chalcone derivatives: promising starting points for drug design. Molecules 2017 22:1210

GraphPad Prism version 7.00 for Windows, GraphPad Software, La Jolla, California, USA, www.graphpad.com

Harborne JB, Williams CA (2000) Advances in flavonoid research since 1992. Phytochemistry 55:481-504

Harris IS, Treloar AE, Inoue S, Sasaki M, Gorrini C, Lee KC, Yung KY, Brenner D, Knobbe-Thomsen CB, Cox MA, Elia A, Berger T, Cescon DW, Adeoye A, Brustle A, Molyneux SD, Mason JM, Li WY, Yamamoto K, Wakeham A, Berman HK, Khokha R, Done SJ, Terrance J, Kavanagh TJ, Lam CW, Mak TW(2015) Glutathione and thioredoxin antioxidant pathways synergize to drive cancer initiation and progression Cancer Cell 27:211-222

Jin YL, Jin XY, Jin F, Sohn DH, Kim HS (2008) Structure activity relationship studies of anti-inflammatory TMMC derivatives: 4Dimethylamino group on the B ring responsible for lowering the potency. Arch Pharm Res 31:1145-1152

Krishnan R, Binkley JS, Seeger R, Pople JA (1980) Self-consistent molecular orbital methods. XX. A basis set for correlated wavefunctions. J Chem Phys 72:650-654

Lavabre JCMD, Pimienta V, Levy G (1993) Reversible, mixed firstand second-order and autocatalytic reactions as particular cases of a single kinetic rate law. J Phys Chem 97:5321-5326

Lindamulage IK, Vu H-Y, Karthikeyan C, Knockleby J, Lee Y-F, Trivedi P, Lee H (2017) Novel quinolone chalcones targeting colchicinebinding pocket kill multidrug-resistant cancer cells by inhibiting tubulin activity and MRP1 function. Sci. Reports 7:10298.

Macrae CF, Edgington PR, McCabe P, Pidcock E, Shields GP, Taylor R, Towler M, van de Streek J (2006) Mercury: visualization and analysis of crystal structures. J Appl Crystallogr 39:453-457

Martel-Frachet V, Keramidas M, Nurisso A, DeBonis S, Rome C, Coll J-L, Boumendjel A, Skoufias DA, Ronot X (2015) IPP51, a chalcone acting as a microtubule inhibitor with in vivo antitumor activity against bladder carcinoma. Oncotarget 6:14669-14686

Maydt D, De Spirt S, Muschelknautz C, Stahl W, Müller TJJ (2013) Chemical reactivity and biological activity of chalcones and other $\alpha, \beta$-unsaturated carbonyl compounds. Xenobiotica 43:711-718

Mosmann T (1983) Rapid colorimetric assay for cellular growth and survival: application to proliferation and cytotoxicity assays. J Immunol Meth 65:55-63

Nowakowska $Z$ (2007) A review of anti-infective and antiinflammatory chalcones. Eur J Med Chem 42:125-137

Ortega AL, Mena S, Estrela JM (2011) Glutathione in cancer cell death. Cancers 3:1285-1310
Osama M, Hussain W, Hussain HT (2014) Two novel four fused ring system benzo-pyrano-triazolo-thiadiazepines from 2-phenyl- $E-3-$ benzylidenechroman-4-ones: Synthesis, stereostructure and cytotoxic activity. Int J Modern Org Chem 3:18-33

Perjési P, Maász G, Reisch R, Benko A (2012) E)-2-Benzylidenebenzocyclanones: Part VII. Investigation of the conjugation reaction of two cytotoxic cyclic chalcone analogues with glutathione: An HPLC-MS study. Monatsh Chem 143:1107-1114

Perjési P, Perez CN, Bernardes A, d'Oliveira GD, Kenari F (2019) The chemistry of GST-catalyzed reactions. In: Perjési P (ed) Glutathione: biosynthesis, functions and biological implications. Nova Science Publishers, New York, NY, p 373-409

Powis G, Gasdaska JR, Baker A (1997) Redox signaling and the control of cell growth and death. In: Sies H (ed) Advances in pharmacology Vol 38. Academic Press, San Diego, p 329-359

Rahman MA (2011) Chalcone: a valuable insight into the recent advances and potential. Chem Sci J 29:1-16

Rozmer Z, Perjési P (2016) Naturally occurring chalcones and their biological activities. Phytochem Rev 15:87-120

Rozmer Z, Berki T, Perjési P (2006) Different cell proliferation effects of two cyclic chalcone analogues in Jurkat lymphocytes. Toxicol in Vitro 20:1354-1362

Sahu NK, Balbhadra SS, Choudhary J, Kohli DV (2012) Exploring pharmacological significance of chalcone scaffold: A review. Curr Med Chem 19:209-225

Schlegel HB, Binkley JS, J. Pople A (1984) First and second derivatives of two electron integrals over Cartesian Gaussians using Rys polynomials. J Chem Phys 80:1976

Sheldrick GM (2008) A short history of SHELX. Acta Crystallogr Sect A Found Crystallogr 64:112-122

Sing P, Anand A, Kumar V (2014) Recent developments in biological activities of chalcones: a mini review. Eur J Med Chem 85:758-777

Skehan P, Storeng R, Scudiero D, Monks A, McMahon J, Vistica D, Warren J, Bokesch H, Kenney S, Boyd M (1980) New colorimetric cytotoxicity assay for anti-cancer drug screening. J Natl Cancer Inst 82:1107-1112

Stanton R, Gernert KM, Nettles JH, Aneja R (2011) Drugs that target dynamic microtubules: a new molecular perspective. Med Res Rev 31:443-481

Traverso N, Ricciarelli R, Nitti M, Marengo B, Furfaro AL, Pronzato MA, Marinari UM, Domenicotti C (2013) Role of glutathione in cancer progression and chemoresistance. Oxid Med Cell Longev 2013:972913

Vasková J (2019) Diverse effects of glutathione in the pathophysiology of some organ diseases. In: Perjési P (ed) Glutathione: biosynthesis, functions and biological implications. Nova Science Publishers, New York, NY, p 169-188

Wang J, Wang S, Song D, Zhao D, Sha Y, Jiang Y, Jing Y, Cheng M (2009) Chalcone derivatives inhibit glutathione S-transferase P1-1 activity: Insights into the interaction mode of a,b-unsaturated carbonyl compounds. Chem Biol Drug Res 73:511-514

Yanai T, Tew DP, Handy NC (2004) A new hybrid exchange-correlation functional using the Coulomb-attenuating method (CAM-B3LYP). Chem Phys Lett 393:51-57

Zhuang C, Zhang W, Sheng C, Zhang W, Xing C, Miao Z (2017) Chalcone: a privileged structure in medicinal chemistry. Chem. Rev 117:7762-7810 